\title{
Altas Habilidades /Superdotação: Mitos e Dilemas Docentes na Indicação para o Atendimento
}

\author{
High Abilities/highly Gifted: \\ Myths and Quandaries in the Indication for Attendance
}

Altas Habilidades/superdotación: Mitos y Dilemas Docentes en la Indicación para el Servicio

Sonia Maria Lourenço de Azevedo \& Marsyl Bulkool Mettrau

Universidade Salgado de Oliveira

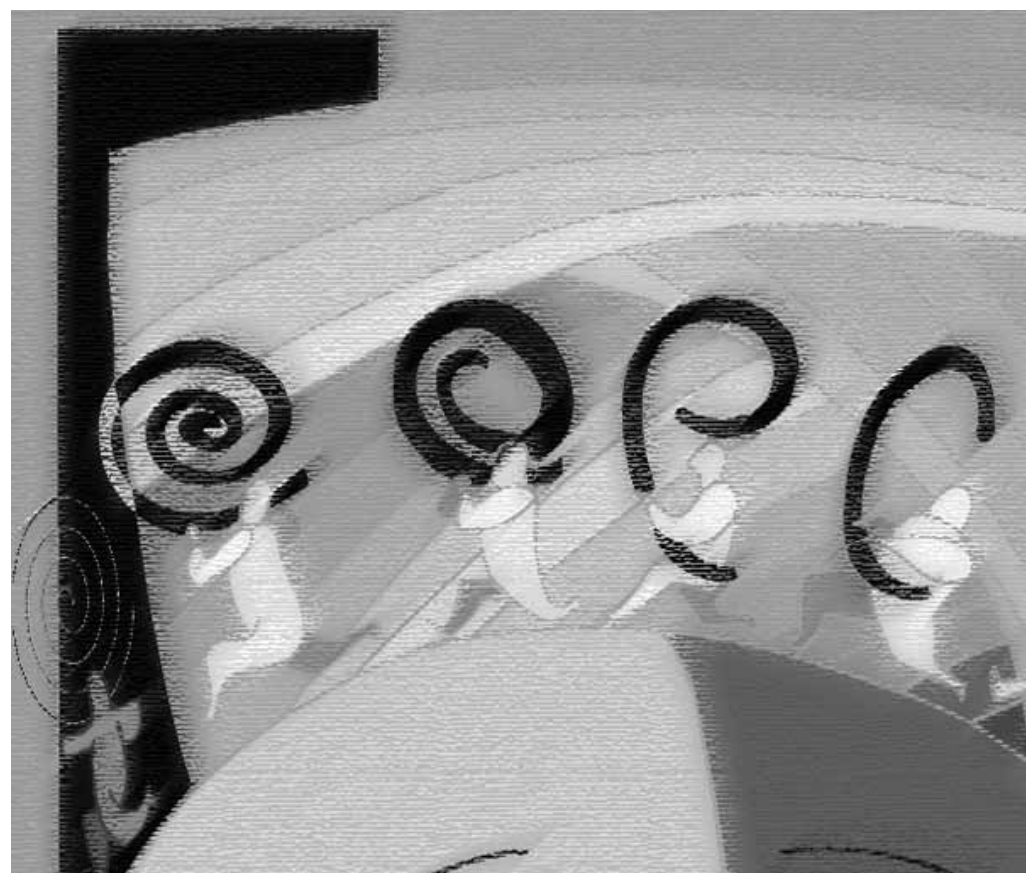


Resumo: O baixo quantitativo de indicação de alunos com altas habilidades/superdotação apontado pelos professores de um Município da periferia do Rio de Janeiro motivou a investigação das possíveis dificuldades encontradas pelos professores nesse processo. Os sujeitos desta pesquisa são 52 professores divididos em dois grupos: 26 professores que indicaram alunos para o programa de alunos com altas habilidades/ superdotação da Secretaria Municipal de Educação desse Município (grupo 1), e 26 professores que não indicaram alunos (grupo 2). Os fatores utilizados nesta pesquisa foram: (a) perfil sociodemográfico dos respondentes; (b) levantamento de possíveis elementos da representação social desse professor por meio dos termos indutores: altas habilidades/superdotação e educação especial; (c) três dilemas baseados na teoria de julgamento moral e nos mitos referentes a altas habilidades/superdotação. Conclui-se que, em ambos os grupos, há fortes indícios de que os mitos acerca das altas habilidades/superdotação influenciam a indicação/não indicação desses alunos, e que esses mitos devem ser discutidos junto aos professores de modo a facilitar a indicação.

Palavras-chave: Altas habilidades. Superdotados. Mitos. Dilemas.

\begin{abstract}
The low quantitative of high abilities/highly gifted pupils indication carried through by the teachers of a peripheral city in Rio de Janeiro is investigated in this work with the objective of verifying the difficulties found by the teacher in this process. Despite the quantitative of schools that directed pupils for the program it has been low through the evaluations evidences that the orientations worked, throughout the qualifications on the subject had favoured the identification of these pupils. The subjects of this research are constituted by the respondent professors who had participated in the program attendance implantation in DC and are divided in the research in two groups: 26 teachers who had indicated pupils for the program (group 1) and 26 professors who had not indicated pupils (group 2). The instruments applied in this research were: (a) demographic profile of the respondents, what segment they teach, how long they have teaching and their age; b) a survey of the possible elements of the social representation of this teacher through the inductive terms: high abilities/highly gifted and special education; (c) three quandaries based on the theory of moral judgment and on myths refering to the high abilities/highly gifted. Thus, there were strong indications that the myths about the high abilities/highly gifted influence the indication/not indication of these pupils and that these myths must be worked next to the teachers in order to facilitate the indication and to extend their knowledge concerning this subject.
\end{abstract}

Keywords: High abilities. Highly gifted. Myths. Quandaries.

Resumen: El bajo cuantitativo de indicación de alumnos con altas habilidades/superdotación señalado por los maestros de un Municipio de la periferia de Río de Janeiro motivó la averiguación de las posibles dificultades encontradas por los maestros en ese proceso. Los sujetos de esta pesquisa son 52 maestros divididos en dos grupos: 26 maestros que indicaron alumnos para el programa de alumnos con altas habilidades/superdotación de la Secretaría Municipal de Educación de ese Municipio (grupo 1), y 26 maestros que no indicaron alumnos (grupo 2). Los factores utilizados en esta pesquisa fueron: (a) perfil sociodemográfico de los respondedores; (b) levantamiento de posibles elementos de la representación social de ese maestro por medio de los términos inductores: altas habilidades/superdotación y educación especial; (c) tres dilemas basados en la teoría de juicio moral y en los mitos referentes a altas habilidades/ superdotación. Se concluye que, en ambos grupos, hay fuertes indicios de que los mitos acerca de las altas habilidades/superdotación influencian la indicación/no indicación de esos alumnos, y que esos mitos deben ser discutidos junto a los maestros de modo que facilite la indicación.

Palabras clave: Altas habilidades. Superdotados. Mitos. Dilemas.

\section{O Ministério da Educação e Secretaria} de Educação Especial (MEC/SEE, 2005), em publicação voltada para a educação infantil e a inclusão, sugere, no caso do aluno com altas habilidades/superdotação, atendimento suplementar para aprofundar e/ou enriquecer o currículo escolar. O atendimento suplementar dado a esses alunos da educação infantil deverá iniciar-se por volta dos quatro anos de idade, em sala de recursos, com o seguinte objetivo:
Oferecer oportunidade para que eles explorem áreas de interesse, aprofundem conhecimentos já adquiridos e desenvolvam habilidades relacionadas à criatividade, resolução de problemas e raciocínio lógico. Além disso, esse atendimento contribui para o desenvolvimento de habilidades sociais e emocionais, como cooperação e autoconceito, e propicia ao aluno oportunidade para eles vivenciarem o processo de aprendizagem com motivação. (MEC/SEE, 2005, p. 21) 
Constata-se, a partir da citação, a importância de identificar esse aluno para propor um atendimento diferenciado. A identificação terá sentido se existir uma proposta pedagógica que atenda as necessidades dos alunos com características específicas.

Nesse sentido, o Ministério da Educação e a Secretaria de Educação Especial (MEC/SEE, 2007), nas estratégias de identificação de alunos com altas habilidades/superdotação, publicou:

A identificação e a avaliação do aluno com altas habilidades/superdotação têm se constituído um desafio para educadores e psicólogos. A simples rotulação de um indivíduo com altas habilidades/ superdotação não tem valor ou importância se não for contextualizada dentro de um planejamento pedagógico ou de uma orientação educacional. (p. 55)

A identificação deve ser realizada através de observação sistemática de seus traços e, também, através do desempenho ao longo de tarefas. Utilizando o modelo triádico da superdotação desenvolvido por Renzulli (1978, 2005), Mönks (1992) e Mönks e Katzko (2005), os portadores de altas habilidades destacam-se por apresentarem um conjunto de três traços marcantes que funcionam dinâmica e conjuntamente, como: capacidade acima da média, criatividade em alto nível e envolvimento com a tarefa.

Segundo o MEC/SEE (2007), o processo de identificação deve envolver uma avaliação abrangente multidimensional que englobe variados instrumentos e diversas fontes de informações como indivíduos, professores, colegas de turma e familiares. Além disso, a identificação desses alunos deve ter como base referenciais teóricos consistentes e resultados de pesquisa sobre o tema. Dessa forma, faz-se necessário que essa identificação seja realizada por profissionais competentes e por especialistas no assunto. $\mathrm{O}$ professor desempenha um papel significativo nesse processo, pois ele: (a) observa o aluno em sua sala de aula e, através dessa observação, (b) faz a indicação dos mesmos se apresentarem características de altas habilidades/superdotação para compor a avaliação mais global. Para que ocorra a identificação dos alunos pelos profissionais que avaliam as altas habilidades/superdotação, faz-se necessária, também, a indicação através de seus professores, colegas, pais e familiares, entre outros.

O aluno é indicado para avaliação e participação em programas especiais existentes quando são observados, em sala de aula, suas habilidades, talentos, envolvimento com a tarefa e criatividade. A falta de indicação e as dificuldades na identificação desses alunos são analisadas a seguir, tendo como base o exame dos nove mitos da superdotação segundo Winner (1998). Este estudo faz uma análise dos dados obtidos por meio da aplicação de questionário em um total de 52 professores da Rede Municipal de Educação da periferia do Estado do Rio de Janeiro, relacionandoos aos mitos que pessoas, professores e outros profissionais da educação têm sobre altas habilidades/superdotação, motivando a investigação das possíveis dificuldades assinaladas durante o processo de indicação e as possibilidades de atendimento específico. Assim sendo, ressalta-se a importância de separar os mitos já conhecidos da realidade observada e descrita neste trabalho.

É importante destacar que os mitos relacionados às altas habilidades/superdotação influenciaram na indicação/não indicação desses alunos para o programa, como foi observado nas respostas dos grupos respondentes. Os mitos da superdotação são estudados por alguns autores, sendo Winner (1998) a autora que embasa esta pesquisa. 
A referida autora propõe nove mitos sobre superdotação: (1) superdotação global; (2): talentosos, porém não superdotados; (3) QI excepcional; (4) e (5): biologia versus ambiente; (6) pai dominado; (7) excessiva saúde psicológica; (8) todas as crianças são superdotadas e (9) as crianças superdotadas se tornam adultos eminentes.

A formação desse professor é processual, construída ao longo de sua prática e da busca por formação continuada. A prática docente é parte de uma realidade concreta, em sala de aula; dinâmica, no dia a dia, e subjetiva, carregada de valores e crenças que o professor traz consigo em suas diversas vivências e que vão sustentar a sua relação com o seu aluno e a sua prática pedagógica. Essa realidade é construída no cotidiano histórico-social, dentro e fora do espaço escolar.

A representação social que o professor tem do seu aluno está intimamente ligada à sua prática pedagógica e à relação estabelecida entre professor e aluno (Mettrau, 2000). Dessa forma, acredita-se que, se o professor tem enraizados os mitos da superdotação (Winner, 1998), ele tenderá a não observar esse aluno em sala de aula devido às suas crenças e mitos sobre as já citadas características desse aluno. Referindo-se às representações sociais, Moscovici (1981) descreve:

Por representações sociais, entendemos um conjunto de conceitos, proposições e explicações originado na vida cotidiana no curso das comunicações interpessoais. Elas são o equivalente, em nossa sociedade, dos mitos e sistemas de crenças das sociedades tradicionais; podem também ser vistas como a versão contemporânea do senso comum (p.181).

Sendo, portanto, essas representações, o resultado de ações e/ou valores construídos ao longo da vida, o ato de indicar/não indicar alunos para um programa de atendimento tem influências, não apenas teóricas, referindo-se aos textos discutidos nas formações, mas também sociohistóricas e valorativas. Esse último aspecto refere-se ao reconhecimento e à aceitação do fato de haver alunos com tais características em escolas de periferia.

O fazer pedagógico tem dificuldades em transpor muitos desses mitos e crenças dos quais o professor, em geral, está impregnado. As representações sociais já trazidas por eles interferem, sobremaneira, nos processos de identificação, seleção e escolha de quem tem direito ou não ao atendimento específico em programas voltados para pessoas com altas habilidades/superdotação (Mettrau, 1995). Falar em direito ao atendimento específico para esses sujeitos, ligando tal temática apenas às determinações legais, já seria suficiente se fosse cumprido o que está previsto na legislação, porém, não é o que se observa no painel educacional do país onde grande parte das leis educacionais não é cumprida. É nesse aspecto que direito legal e direito moral se distinguem e justificam muitas das questões relacionadas à não indicação das pessoas estudadas nesta pesquisa.

A análise de dilemas baseados na teoria de Kohlberg (1984), com o grupo de professores respondentes, foi utilizada como estratégia para tentar explicar e entender porque apenas um pequeno grupo de unidades escolares (37), de um total de 109, indicou alunos para o Programa Especial de Atendimento a pessoas com altas habilidades/superdotação ali instalado. Planejou-se relacionar os mitos aos dilemas e às reflexões morais e legais apresentadas pelos professores, e tal decisão ampliou a visão sobre as possíveis dificuldades na indicação desses alunos. Acredita-se que a análise dos dilemas morais com base em Kohlberg (1984) referenciados nos mitos relativos às altas habilidades/superdotação de Winner (1998) tenha sido um novo caminho para auxiliar o entendimento da baixa indicação de alunos, conforme se 
verificou nesta pesquisa. Por que seriam os mitos que envolvem o tema superdotação/ altas habilidades tão significativos a ponto de se sobrepor a uma determinação legal, no momento de indicação dos alunos? Essa é uma questão que norteou nosso estudo.

\section{Método}

\section{Participantes}

Participaram deste estudo 52 professores da Rede Municipal de Ensino de um Município da periferia do Estado do Rio de Janeiro, onde se deu a implantação de um programa de atendimento a alunos com altas habilidades/ superdotação. Esses professores foram os mesmos que participaram das reuniões de capacitação sobre esse tema, realizadas pela equipe de educação especial do referido Município. Nessa capacitação, houve a participação de todas as unidades do Município, através de professores representantes, diretores e especialistas: orientadores educacionais e orientadores pedagógicos. Das 109 escolas envolvidas, porém, somente 37 delas, o que corresponde a $33,94 \%$ do total, encaminharam alunos com indicadores de altas habilidades/ superdotação.

\section{Instrumentos de coleta de dados}

1- Levantamento do perfil sociodemográfico

No levantamento do perfil sociodemográfico, foram coletadas informações dos participantes por meio de quatro perguntas, a fim de levantar dados a respeito do nível de formação, do segmento que atua, do tempo de exercício de magistério e da faixa etária. Uma quinta pergunta, nesse instrumento de dados, destina-se a identificar se o professor havia ou não indicado alunos para o Programa de Altas Habilidades.
2- Evocação de palavras

A fim de levantar os possíveis elementos da representação social dos professores respondentes, utilizou-se o método de evocação de palavras a partir de 03 (três) termos indutores. Foi solicitado aos respondentes que escrevessem até três palavras ou expressões que viessem à lembrança ao se depararem com os seguintes termos indutores: (a) pessoas com altas habilidades/superdotação e (b) educação especial.

Fez-se o levantamento dos resultados através de porcentagem relacionada a essas evocações. Ressalta-se que as interpretações dos resultados e as conclusões posteriores não têm o objetivo de generalizações para uma população maior, mas de levantar dados que possam esclarecer questões e ampliar estudos sobre a temática.

3- Dilemas com base nos mitos acerca da superdotação

Após a coleta de dados, foram aplicadas questões voltadas para a análise de três dilemas, baseados na teoria de julgamento moral, de Kohlberg (1984), cujos temas se relacionavam à temática dos mitos acerca das pessoas com altas habilidades/superdotação (Winner, 1998). Tais dilemas foram construídos pelo grupo de mestrandos e já empregados em trabalho anterior (Mettrau et al., 2007), e foram respondidos pelos participantes da pesquisa a fim de analisar como cada professor julga ser necessário ou não o atendimento dos alunos em questão.

Procedimentos de coleta de dados

Inicialmente, foi feito contato com a Secretaria Municipal de Educação solicitando autorização para a realização da pesquisa de campo. Através de consulta da frequência de professores e demais participantes à época da implantação do referido programa, 
identificaram-se as escolas e os profissionais que haviam participado do mesmo. Após essa localização, foi enviado a cada professor o questionário, com uma carta explicativa sobre a pesquisa.

Dos questionários preenchidos, havia 26 de professores respondentes que indicaram alunos para o programa e 26 que não indicaram.

\section{Resultados e discussão}

\section{Perfil sociodemográfico dos participantes da pesquisa}

Tabela 1. Perfil sociodemográfico dos professores.

\begin{tabular}{llllll}
\hline Informação & Categoria & Frequência & $\%$ & Frequência & $\%$ \\
\hline Segmento em & Ed. infantil & Grupo 1 & & Grupo 2 & \\
que atua & Ed. fundamental & 16 & 15,38 & 4 & 15,38 \\
& Ed. especial & 2 & 61,54 & 14 & 53,84 \\
& Outros & 4 & 7,70 & 3 & 11,54 \\
\hline Tempo de & 1 a 5 anos & 0 & 15,38 & 5 & 19,23 \\
exercício no & 6 a 15 anos & 8 & 0 & 0 & 0 \\
magistério & 16 a 24 anos & 12 & 46,76 & 4 & 15,38 \\
& Mais de 25 anos & 6 & 23,08 & 6 & 57,70 \\
& aposentada & 0 & 0 & 0 & 23,08 \\
& Em branco & 0 & 0 & 1 & 0 \\
Faixa & 18 a 25 anos & 0 & 0 & 0 & 3,84 \\
etária & 26 a 35 anos & 4 & 15,38 & 4 & 0 \\
& 36 a 45 anos & 11 & 42,30 & 2 & 15,38 \\
& 46 a 55 anos & 6 & 23,08 & 7 & 46,16 \\
& Mais de 56 anos & 3 & 11,54 & 3 & 26,90 \\
& Em branco & 2 & 7,70 & 0 & 11,54 \\
\end{tabular}

Verifica-se, nos dois grupos de respondentes, certo equilíbrio quanto ao segmento em que atua no magistério, e à faixa etária tal como apresentado na Tabela 1.

Em relação ao nível de formação, verifica-se pequena diferença entre os dois grupos de professores. Dos professores que indicaram alunos, 26,90\% têm formação superior, e 57,70\% têm pós-graduação. Já entre os professores que não indicaram alunos, 46,16\% têm formação superior, e 38,46\% tem pós-graduação. Observa-se, ainda, que somente um professor (3,84\%), pertencente ao grupo dos que não indicou alunos, tem mestrado. Ressalta-se que, apesar da diferença quanto ao nível de formação, os dois grupos receberam formação continuada sobre altas habilidades/ superdotação na implantação do referido programa, durante o período de um ano, organizada em encontros semanais.

A evocação de três palavras por meio do termo indutor: pessoas com altas habilidades/ superdotação 
As evocações de palavras obtidas por meio do termo indutor pessoas com altas habilidades/ superdotação, pelos professores respondentes do grupo 1 e do grupo 2 foram analisadas e classificadas em categorias. O número elevado de categorias consideradas se deve ao fato de se respeitar as evocações dos respondentes. Palavras evocadas uma única vez e que não se encaixavam em nenhuma categoria construída, através da análise do conteúdo, são apontadas somente como palavras, e não como categorias.

Quanto à evocação de palavras sobre pessoas com altas habilidades, no grupo 1 , são encontradas as maiores frequências nas categorias: criatividade $(19,23 \%)$, inteligência $(15,38 \%)$ e dificuldades (16,67\%). No grupo 2 , as evocações analisadas com maior frequência foram: desajuste e dificuldade $(14,29 \%)$, genialidade $(12,99 \%)$, inteligência elevada $(11,69 \%)$, criatividade $(11,69 \%)$ e aprendizagem (10,38\%).

Comparando os dois grupos quanto ao termo indutor aqui utilizado, observa-se que o grupo 1 evocou as palavras com base na literatura que trata desse tema com maior frequência. A criatividade, que foi a categoria mais evocada, é uma das características da pessoa com altas habilidades/superdotação segundo o modelo triádico da superdotação desenvolvido por Renzulli (1978, 2005), Mönks (1992) e Mönks e Katzko (2005). Já o grupo 2 teve a sua maior frequência nas dificuldades que alunos com características de altas habilidades/superdotação apresentam, e faz uma associação entre alunos superdotados e alunos com problemas comportamentais, o que não se pode confirmar na maioria dos casos. Observa-se ainda que o grupo 1 também evoca palavras que correspondem às dificuldades desses alunos, porém estas não estão ligadas aos mitos da superdotação, e sim, ao fato de que esses alunos podem apresentar dificuldades na aprendizagem de algumas matérias como qualquer outro aluno.
É interessante assinalar a baixa frequência $(2,56 \%)$ da evocação de duas palavras que estão relacionadas ao envolvimento com a tarefa: gosta de fazer tudo bem feito e é esforçado, pois essas expressões também contemplam o conceito aqui utilizado e acima referido.

\section{Evocação de três palavras por meio do termo indutor: atendimento em educação especial}

Quanto à evocação de palavras sobre educação especial, no grupo 1, são encontradas as maiores frequências nas categorias: problemas no atendimento dos alunos com altas habilidades/ superdotação em educação especial (18,42\%), característica do professor de educação especial e dificuldade do aluno (15,79\%), e importância da formação desse professor (13,16\%). No grupo 2, as evocações analisadas com maior frequência foram: características que o professor de educação especial deve ter $(18,42 \%)$, dificuldades encontradas no exercício e no atendimento da educação especial $(17,10 \%)$ e importância da capacitação profissional por meio de formação $(14,47 \%)$.

Essas evocações apontam uma crítica ao atendimento e à organização da educação especial por meio das seguintes palavras: atendimento inadequado, inexistência, não padronizado, evasivo, burocrático. Duas categorias de respostas obtiveram baixa frequência $(2,63 \%)$ : inclusão e estímulo. Ambas as categorias, embora significativas, foram pouco evocadas pelo grupo 2, revelando a necessidade de se realizar estudos posteriores sobre esse tema buscando uma mudança de paradigma: deixa de existir a dicotomia ensino especial/ensino regular e a escola passa a ser inclusiva, para todos (Werneck, 1999).

Tanto o grupo 1 quanto o grupo 2 evidenciam a necessidade que o professor sente em relação a cursos e formações que 
enriqueçam seu fazer pedagógico, pois foram citados diversos termos que remetem às dificuldades encontradas no atendimento em educação especial e às suas relações com a pouca formação específica recebida nessa modalidade de ensino.

Os objetivos que orientam essas análises através das representações sociais partem de duas perspectivas que, segundo Rangel (2007), se associam e se complementam. A primeira perspectiva enfatiza o sentido das representações como forma de conhecimento prático, ou seja, o modo como são construídos e adquiridos os conceitos no processo de ensino-aprendizagem. A segunda perspectiva sugere aos professores considerar a possibilidade de aplicação didática das categorias de representação social e dar particular atenção à estrutura dessas categorias assim como aos princípios e noções que fundamentam e explicam o seu núcleo central e os elementos periféricos (Rangel, 2007).

Dessa forma, se reconhece, na teoria de representação social, a possibilidade de contribuir com o estudo no campo das altas habilidades/superdotação, em que as dificuldades encontradas pelos professores para indicar/não indicar apresentam as duas perspectivas acima observadas: o conhecimento adquirido nas formações e o reconhecimento da existência desses alunos nas salas de aula, permitindo tornar efetiva a indicação e o atendimento específico às suas necessidades especiais.

\section{Os dilemas}

\section{Análise quantitativa}

A análise quantitativa foi realizada através do programa SPSS for Windows, versão 15.0, utilizando o Teste T para grupos relacionados, a fim de verificar se há diferenças significativas nas respostas assinaladas pelos dois grupos respondentes ( 1 e 2 ).

No que se refere aos dilemas sobre mitos acerca da superdotação, verifica-se que as respostas foram significativamente diferentes $(p=0,02)$ entre os dois grupos de professores desta pesquisa: média de 19,53 com desvio padrão de 1,98 para os professores do grupo 1 , e média de 16,30 com desvio padrão de 4,48 para professores do grupo 2. As diferenças observadas nas médias refletem as diferenças reais nos dois grupos de pesquisa, e tais diferenças mostram que o grupo 2 apresentou maior número de respostas pautadas em mitos da superdotação, diferentemente do grupo 1, que embasou a maior parte de suas respostas em dados encontrados na literatura sobre o tema.

\section{Análise qualitativa}

Dilema 1: direito ao atendimento especializado

Esse dilema está relacionado ao mito da superdotação (Winner, 1999), que diz que superdotados se tornam adultos eminentes, não levando em consideração a importância da educação especial. Os profissionais da escola que creem nesse mito não consideram a importância do ambiente educacional na trajetória de vida desses alunos. Nesse dilema, questiona-se também o aspecto legal da indicação/atendimento desses alunos e sua obrigatoriedade legal, quase nunca seguida nas unidades escolares. São destacados os seguintes questionamentos: (a) os alunos com altas habilidades/superdotação aprendem tudo sozinhos, sem problemas?; (b) os educadores podem escolher se devem encaminhar, seguindo a legislação, os alunos com déficits e não encaminhar os alunos com altas habilidades/superdotação?, e (c) os educadores que não encaminham os alunos com altas habilidades/superdotação para atendimento especializado deveriam sofrer sansões oficiais? 
Segundo Winner

(1998), é mesmo um mito considerar que o superdotado não necessite de acompanhamento em sua trajetória de vida e que será um adulto eminente independentemente da escola e das oportunidades que a educação possa the oferecer bem como de sua aceitação na família.
Tanto o grupo 1 quanto o grupo 2 responderam, em sua maioria, que os alunos não aprendem tudo sozinhos. As justificativas utilizadas para essas respostas foram diferentes nos dois grupos. O grupo 1 ressaltou a falta de conhecimento dos profissionais que lidam com tais alunos; por isso, muitas vezes são considerados problemáticos pelos professores durante o fazer pedagógico, e são, assim, discriminados. O grupo 2 ressaltou a dificuldade que os alunos com altas habilidades/ superdotação têm em lidar com suas capacidades, sendo essas capacidades consideradas por alguns professores privilégio, e não resultado de empenho e esforço. Dessa forma, em ambos os grupos, verifica-se também o 4ㅇ e 5 o mito, "tudo para o superdotado é fácil, e ele não precisa de muito esforço". A realidade é que o superdotado tem alta habilidade, mas necessita de esforço e estudo para trabalhar com todo o seu potencial. Segundo Winner (1998), é mesmo um mito considerar que o superdotado não necessite de acompanhamento em sua trajetória de vida e que será um adulto eminente independentemente da escola e das oportunidades que a educação possa Ihe oferecer bem como de sua aceitação na família.

A maioria dos professores do grupo 1 respondeu que devem ser encaminhados seguindo a legislação. Ressalta-se a justificativa dada por um professor desse grupo, o qual evidencia que "não é questão de escolher quem encaminhar, mas sim, de locais apropriados para receber os encaminhamentos. Havendo esses locais, não deve haver escolhas", resposta muito afirmativa e correta; outro professor descreve que é justo, "mas, muitas vezes, a própria família não tem vontade de encaminhar", transformando o direito ao encaminhamento em opção da família. A maioria dos professores do grupo 2 também respondeu que devem encaminhar seguindo a legislação.
Ressalta-se a justificativa apresentada por um professor, que respondeu que "o educador tem livre escolha se pode ou não obedecer à legislação". Outra resposta é justificada pelo professor como "o encaminhamento deveria ser opção do aluno/responsável. Diferentemente do aluno com déficit mental, o aluno com altas habilidades/superdotação pensa por si mesmo, tem instrumentos para refletir sobre suas escolhas", transferindo tal decisão para o aluno/responsável, sem considerar o conhecimento pedagógico/ legislativo que, muitas vezes, estes não recebem, sendo usual o desconhecimento desses aspectos pelo próprio aluno. Essa também é uma opinião que contraria tanto a literatura de educação especial quanto de educação geral, pois todos devemos refletir sobre escolhas não só nesse tema, mas em tudo na vida.

A maioria dos professores do grupo 1 justifica que eles não deveriam receber sanções, mas "deveriam, sim, receber mais informações e orientações sobre o que são as necessidades especiais". A descrença nas políticas públicas para o atendimento das pessoas superdotadas/altas habilidades foi apontada por um professor, que justificou sua resposta afirmando que, "se ele (o professor) tem motivo para não acreditar no que o governo é capaz de fazer, ele não deve sofrer sanções". Um professor levantou a questão da formação deficiente como justificativa para não receber sanções pelo não encaminhamento. É importante relembrar que todos os professores participantes fizeram parte de uma capacitação voltada para o tema altas habilidades/ superdotação, e somente a partir desta o referido Município, onde ocorreu a pesquisa, implantou essa modalidade de atendimento.

Quanto aos professores do grupo 2, é importante ressaltar que todos os professores responderam que não deveriam receber 
sanções. A maioria justificou que o professor necessita de orientação e esclarecimento, e não de sanções. Ressalta-se, nessas justificativas, que o professor fica inseguro na indicação desse aluno, acreditando que deve ter certeza da mesma. Demonstram medo, receio, exatamente pela insegurança trazida pelo pouco saber que acreditam ter. Destaca-se a justificativa de um professor, que descreve que "não é questão de sanção. Estamos lidando com profissionais responsáveis. É mais importante perguntar por que ele não encaminha. Será que ele reconhece esse aluno? Será que acredita na educação especial para os alunos?" Uma das respostas foi que o desconhecimento da legislação é apontado como justificativa para não receber sanções, pois "será que esses educadores estão cientes da legislação e sabem reconhecer alunos com altas habilidades?" Nas justificativas apresentadas nesse grupo, observa-se, por meio da análise dos relatos, que os professores desconhecem também as características comportamentais, o ritmo de aprendizagem e o nível de interesse desse aluno.

Dilema 2: a prova de matemática

Esse dilema está relacionado ao mito da superdotação (Winner, 1998), que afirma que superdotados têm alto desempenho escolar em todas as disciplinas acadêmicas. Os profissionais da escola que creem nesse mito não admitem a hipótese de um possível insucesso, e criam a perspectiva de que tudo seja fácil para esse aluno.

São destacados os seguintes questionamentos: (a) em sua opinião, o aluno com altas habilidades pode vir a ter dificuldades de matemática? (b) você acha que, tendo dificuldades em matemática, o mesmo deixa de ter altas habilidades?
Tanto o grupo 1 como o grupo 2, em sua maioria, responderam que o aluno com altas habilidades/ superdotação poderia ter dificuldade em matemática. Mesmo com essa maioria das respostas, as justificativas apresentadas permanecem vinculadas ao mito da superdotação (Winner, 1998), que demonstra a ideia que o professor tem a respeito sempre bom rendimento escolar do superdotado, relacionando o fato de este ter nota baixa a problemas emocionais ou à metodologia, mas não à realidade de que, nem sempre, esses alunos são superdotados em todas as disciplinas. Deve-se acrescentar que às vezes não apresentam bom rendimento por falta de interesse, de motivação e até mesmo de bom material para estudar, ou mesmo porque não têm o melhor professor, no ponto de vista do aluno.

Verifica-se, nos dois grupos, a presença de visão mítica acerca das altas habilidades/ superdotação, pois o professor que tem essa visão não entende a possibilidade de esse tipo de aluno ter dificuldades. A realidade é que o superdotado, como qualquer outra pessoa, pode apresentar dificuldades, não só nessa matéria como em qualquer outra e até mesmo em mais de uma, e demonstrar ótimos resultados globais e/ou específicos, como, por exemplo, no campo das letras ou da mecânica, entre outros.

Tanto o grupo 1 como o grupo 2 foram unânimes ao responder que o aluno, mesmo tendo dificuldade em matemática, não deixa de ter altas habilidades. A grande maioria dos professores, em ambos os grupos, não deu justificativa em suas respostas. No pequeno grupo de professores que as justificaram, observou-se, entre os dois grupos, diferenças em tais justificativas. A maioria das justificativas do grupo 1 foi direcionada para o fato de esse aluno poder ter habilidades em uma área e dificuldade 
em outra(s), e somente um professor desse grupo respondeu que a dificuldade poderia estar baseada na questão emocional. Outro professor respondeu que a aluna "precisa de atendimento individualizado, como todos os outros com dificuldade". Verifica-se, nesse conjunto de respostas, a necessidade de um atendimento diferenciado e a sinalização da necessidade de uma metodologia adequada. Já a maioria dos professores do grupo 2 justificou a dificuldade devido a diferentes habilidades que o aluno com altas habilidades/superdotação tem e a fatores emocionais vivenciados pelo aluno, que poderiam dificultar a sua aprendizagem. Um pequeno grupo de respostas voltou-se para o fato de esse aluno poder ter habilidades em uma área e dificuldade em outra(s).

Dilema 3: o aluno superdotado

Esse dilema está relacionado ao mito da superdotação (Winner, 1998), que sustenta que superdotados têm um biotipo específico e são ajustados psicologicamente a qualquer situação ou ambiente. Os profissionais da escola que creem nesse mito buscam características físicas e ambientais específicas para indicar/não indicar esses alunos. São destacados os seguintes questionamentos: (a) deveria haver alunos indicados como superdotados em todas as escolas do Brasil?, e (b) a opção de João de sentar-se no fundo da sala e ficar somente com seus livros é uma característica de aluno superdotado?

A maioria dos professores dos dois grupos responderam que há alunos superdotados em todas as escolas brasileiras, apesar de observar que a maioria dessas justificativas, no grupo 1 , é baseada em mitos. Ressalta-se, nesse grupo, a justificativa que diz que "o Brasil precisa de gênios, é legal saber que existem pessoas assim" evidenciando uma visão mítica e ideias equivocadas sobre esse aluno. $\mathrm{O}$ superdotado não é gênio, nem é bom em tudo, e a realidade é que ele necessita de um trabalho diferenciado em sua vida escolar, seja curricular, seja no ritmo pedagógico. O grupo 2 pautou suas justificativas mais nas questões legais. Ressalta-se a justificativa que diz: "é claro que deveria ter bons profissionais em todas as escolas, porém é importante também que os educandos tenham asseguradas as suas necessidades especiais garantidas nas determinações legais já citadas. como, por exemplo, a Lei no 9.394/96, em seu artigo 59, apontando a necessidade de se dar atendimento a esses alunos em todas as regiões do Brasil. Trata-se, portanto, de políticas públicas.

A maioria dos professores dos dois grupos também respondeu que as características apresentadas nesse dilema não o definem

como aluno com altas habilidades/ superdotação, sendo necessárias, conforme as justificativas apresentadas, mais informações sobre o aluno, e não somente sobre os aspectos físicos e comportamentais. Verificase que outro grupo, em sua justificativa, indica que tais características estão relacionadas a problemas emocionais e sociais, e não a superdotação.

Observa-se um dado interessante em uma das respostas do professor referente ao fato de que trabalhar as habilidades traz problemas para o aluno. Algumas questões, nessa justificativa de respostas, poderiam ser levantadas, como: trabalhar habilidades traz problemas? Uma das funções da escola não é trabalhar habilidades? Essas já seriam questões norteadoras para próximas pesquisas.

Apresentar ao grupo de professores pesquisados alguns dos mitos da superdotação (Winner, 1998) por meio da análise de dilemas permitiu que alguns mitos fossem registrados mais significativamente nas suas justificativas, pois responder os dilemas implicou um posicionamento de ideias e 
opiniões em que teoria e subjetividade se misturam e se complementam, confrontando opiniões e atuando como instrumento de desmistificação de tal mito.

\section{Considerações finais}

O baixo quantitativo de indicação de alunos com altas habilidades/superdotação, realizada pelos professores do Município onde se realizou a pesquisa, é investigado neste trabalho com o objetivo de verificar as dificuldades encontradas nesse processo. Ainda que tenha sido baixo o quantitativo de indicações, das 109 escolas envolvidas, somente 37 delas, o que corresponde a $33,94 \%$ do total, encaminharam alunos com indicadores de altas habilidades/superdotação, constatando-se que as orientações trabalhadas ao longo da capacitação sobre o tema favoreceram a indicação/identificação dos alunos nessa rede de ensino. Nesta pesquisa, verificou-se ainda que, comparando os dois grupos de professores respondentes, há significativa diferença no que se refere às evocações de palavras através dos termos indutores pessoas com altas habilidades e educação especial. Nota-se que o grupo 1 evocou palavras encontradas na literatura sobre esse tema com maior frequência do que o grupo 2 .

Ao analisar os três dilemas, ficou evidenciado, nos dois grupos da pesquisa, através das análises das justificativas dos professores, a existência de alguns mitos da superdotação (Winner, 1998). Esses mitos, conforme nosso pensamento inicial, dificultam a observação do aluno em sala de aula e, em consequência, sua indicação para atendimento específico. $\mathrm{O}$ mito mais encontrado nesta pesquisa foi que os superdotados são alunos academicamente superiores e sempre têm bom rendimento escolar, e isso nem sempre é real, pois eles nem sempre apresentam bom rendimento escolar e raramente são superdotados em todas as matérias.
Outro mito encontrado na pesquisa é que esse aluno não necessita de atendimento especial, mas a realidade é que esses alunos necessitam de atendimento diferenciado, sendo este garantido em Lei. Os profissionais que têm essa visão mítica propõem uma educação igual para todos os alunos, não acreditando no atendimento especial, e isso também deve ser considerado para análise, pois a educação igual e com oportunidade para todos não descarta as especificidades amparadas no atendimento especial.

Observa-se, nos grupos de respostas apresentadas, que o professor tem a visão de que educação especial é modalidade de ensino voltada apenas para alunos com deficiência; dessa forma, o superdotado/altas habilidades não faria parte dessa modalidade. A questão levantada para estudos posteriores é: a educação especial seria realmente a modalidade de ensino em que esses alunos deveriam ser atendidos? É uma pergunta, como muitas, que necessita de resposta.

O professor, neste estudo, afirma que, para atuar com esse aluno, é necessário ter as seguintes características: ser sensível, ter amor à profissão, dedicação, entrega e garra, entre outras. Poderíamos levantar questões como: qual a importância do aspecto técnico e profissional? E a metodologia? Seria realmente a educação especial um trabalho que exige somente amor e entrega, conforme sugerem alguns professores neste estudo?

Outro ponto refere-se ao fato de, apesar de os professores acreditarem na existência de alunos com altas habilidades/superdotação em todas as escolas, ter havido um baixo número de indicações nessa questão. Deve-se lembrar que esse Município é localizado na periferia do Rio de Janeiro, cujos moradores possuem grandes dificuldades econômicas e sociais. Acreditar na existência de alunos superdotados em todas as escolas, independentemente de classe socioeconômica, etnia, sexo e localidade, traz 
a necessidade de serem discutidos não só os aspectos legais e teóricos relacionados ao tema mas também os mitos que há por trás de cada indicação/não indicação.

Desse modo, percebe-se que determinados mitos em relação à superdotação, categorizados por Winner (1998), persistem juntos aos profissionais da educação, e, por isso, acreditamos que o estudo e a compreensão dos mitos aqui descritos podem ser uma estratégia facilitadora para melhor entendimento desse tema, favorecendo a indicação desses alunos pelos professores e possibilitando identificação e atendimento específico, que foi a pretensão do estudo. 
Sonia Maria Lourenço de Azevedo*

Mestre em Psicologia Social. Universidade Salgado de Oliveira, psicóloga educacional da Prefeitura Municipal de Duque de Caxias, RJ - Brasil.

\section{Marsyl Bulkool Mettrau}

Doutora em Educação e Psicologia da Educação, Universidade do Minho, Braga - Portugal. Professora titular da Universidade Salgado de Oliveira, Rio de Janeiro, RJ - Brasil.

E-mail: marsyl@superig.com.br

\section{*Endereço para envio de correspondência:}

Rua Belisário Pena, no 1208, ap. 304, Penha - Rio de Janeiro, RJ - Brasil - CEP: 21020-010.

E-mail: sonietka@uol.com.br

Recebido 17/9/2008, 1aㅡ Reformulação 12/8/2009, 2ª Reformulação 2/10/2009, Aprovado 15/10/2009.

\section{Referências}

Brasil. (1996). Lei no 9.394, de 20 de dezembro de 1996. Estabelece as diretrizes e bases da educação nacional Brasilia, DF.

Kohlberg, L. (1984). Essays on moral development: Vol. 2. The psychology of moral development. San Francisco: Harper \& Row.

Mettrau, M. B. (1995). Concepções e representação da inteligência nos professores: impacto na prática pedagógica (362pp.). Tese de Doutorado em Educação, na Especialização de Psicologia da Educação. Universidade do Minho, Instituto de Educação e Psicologia, Braga, Portugal.

Mettrau, M. B. (2000). Representação social da inteligência e os portadores de altas habilidades. In M. B. Mettrau (Org.), Inteligência: patrimônio social (pp. 1-11). Rio de Janeiro: Dunya.

Mettrau, M. B. (2005). Saberes e práticas da inclusão: a representação social da inteligência e os alunos com altas habilidades. Brasília, DF: Ministério da Educação/Secretaria de Educação Especial.

Mettrau, M. B., Barreto, M. S. L., Barreto, C. M. P. F., Moraes, C., Inácio, D. P., Silva, I., Azevedo, S. M. L., \& Pellegrino, V. B. (2007). Projeto Dilemas. In Anais de Resumos e de Trabalhos Completos, XIV Encontro Nacional da Associação Brasileira de Psicologia Social - ABRAPSO. Diálogos em Psicologia Social [CD-ROM]. Rio de Janeiro.

Ministério da Educação/Secretaria de Educação Especial (2005). Saberes e práticas da inclusão: altas habilidades/superdotação (Educação Infantil). Brasília, DF: Autor.

Ministério da Educação/Secretaria de Educação Especial. (2007). A construção de práticas educacionais para alunos com altas habilidades/superdotação: Vol. 1. Orientação a professores? (D. de S. Fleith, Org.). Brasília, DF: Autor.

Mönks, FJ. (1992). Desarrollo de los adolescentes superdotados. In Y. Benito (Coord.), Desarrollo y educación de los ninõs superdotados (pp. 205-216). Salamanca, Espanha: Amarú Ediciones.
Mönks, F. J., \& Katzko, M. W. (2005). Giftedness and gifted education. In R. Sternberg \& J. Davidson, Conception of giftedness. Cambridge: University of Cambridge.

Moscovici, S. (1981). A representação social da psicanálise. Rio de Janeiro: Zahar.

Moscovici, S. (2000). Das representações coletivas às representações sociais: elementos para uma história. In D. Jodelet (Org.), As representações sociais (pp. 59-67). Rio de Janeiro: EDUERJ.

Rangel, M. T. A. (2007). Ensaio sobre aplicações didáticas da teoria de representação social. Olhar de professor, 10(2), 11-22. Recuperado em 05 de maio de 2008, de http://www.uepg. br/ olhardeprofessor/pdf/revista102_artigo01

Renzulli, J. S. (1978). What makes giftedness? Reexomining a definition. Phi Delta Kappan, 60(3), 180-184.

Renzulli, J. S. (2005).The three-ring conception of giftedness: A developmental model for creative productivity. In R. Sternberg \& J. Davidson, Conception of giftedness. Cambridge: University of Cambridge.

Romney, D. M., \& Pyryt, M. C. (1999). Guilford's concept of social intelligence revisited. High Ability Studies: The Journal of the European Council for High Ability, 10(2), 137-142.

Sá, C. P. (1998). A construção do objeto de pesquisa e representações sociais. Rio de Janeiro: EDUERJ.

Sá, C. P. (2002). Núcleo central das representações sociais. Petrópolis, RJ: Vozes.

Werneck, C. (1999). Sociedade inclusiva. Quem cabe no seu TODOS? (2a ed.). Rio de Janeiro: WVA Ed.

Winner, E. (1998). Crianças superdotadas: mitos e realidades. Porto Alegre: Artes Médicas. 